\title{
Increased neutrophil-lymphocyte ratio is a poor prognostic factor in patients with primary operable and inoperable pancreatic cancer
}

\author{
M Stotz ${ }^{1}$, A Gerger ${ }^{1}$, F Eisner ${ }^{1}$, J Szkandera ${ }^{1}$, H Loibner ${ }^{2}$, A L Ress ${ }^{1}$, P Kornprat ${ }^{3}$, W A Zoughbi ${ }^{4}$, \\ F S Seggewies ${ }^{1}$, C Lackner ${ }^{4}$, T Stojakovic ${ }^{5}$, H Samonigg ${ }^{1}$, G Hoefler ${ }^{4}$ and M Pichler ${ }^{\star}, 1$ \\ ${ }^{1}$ Division of Clinical Oncology, Department of Medicine, Medical University of Graz, Graz, Austria; ${ }^{2}$ Apeiron Biologics AG, Campus \\ Vienna Biocenter 5, Vienna, Austria; ${ }^{3}$ Division of General Surgery, Department of Surgery, Medical University of Graz, Graz, Austria; \\ ${ }^{4}$ Institute of Pathology, Medical University of Graz, Graz, Austria and ${ }^{5}$ Clinical Institute of Medical and Chemical Laboratory \\ Diagnostics, Medical University of Graz, Graz, Austria
}

Background: The neutrophil-lymphocyte ratio (NLR) has been proposed as an indicator of systemic inflammatory response. Previous findings from small-scale studies revealed conflicting results about its independent prognostic significance with regard to different clinical end points in pancreatic cancer (PC) patients. Therefore, the aim of our study was the external validation of the prognostic significance of NLR in a large cohort of PC patients.

Methods: Data from 371 consecutive PC patients, treated between 2004 and 2010 at a single centre, were evaluated retrospectively. The whole cohort was stratified into two groups according to the treatment modality. Group 1 comprised 261 patients with inoperable PC at diagnosis and group 2 comprised 110 patients with surgically resected PC. Cancer-specific survival (CSS) was assessed using the Kaplan-Meier method. To evaluate the independent prognostic significance of the NLR, the modified Glasgow prognostic score (mGPS) and the platelet-lymphocyte ratio univariate and multivariate Cox regression models were applied.

Results: Multivariate analysis identified increased NLR as an independent prognostic factor for inoperable PC patients (hazard ratio $(H R)=2.53$, confidence interval $(C l)=1.64-3.91, P<0.001)$ and surgically resected $P C$ patients $(H R=1.61, C l=1.02-2.53$, $P=0.039$. In inoperable PC patients, the mGPS was associated with poor CSS only in univariate analysis $(\mathrm{HR}=1.44, \mathrm{Cl}=1.04-1.98)$.

Conclusion: Risk prediction for cancer-related end points using NLR does add independent prognostic information to other wellestablished prognostic factors in patients with PC, regardless of the undergoing therapeutic modality. Thus, the NLR should be considered for future individual risk assessment in patients with PC.

In comparison with other tumour entities, the incidence of pancreatic cancer (PC) is low and has not changed a lot during the last two decades (Siegel et al, 2012). Although continuous progress in tumour-specific therapy or outcome could be reached in the majority of malignant diseases, PC management still stays unsatisfying, as hardly any breakthrough in PC therapy has been obtained up to now (David et al, 2009; Tinchon et al, 2013). Therefore, unfortunately the mortality of PC is nearly $100 \%$ after 5-year follow-up (Sharma et al, 2011). The high mortality is linked to local tumour progression and complications of distant 
metastases. Limited potential of curative resection as the only measurement of cure (Sharma et al, 2011) results from non-specific symptoms up to asymptomatic illness for a long time - and despite tremendous advances - still unsatisfying imaging technology (Tummala et al, 2011). Thus, at the time of diagnosis most patients have to rely on palliative chemotherapy, whose efficacy is unsatisfying (Sun et al, 2012). Consequently, intense research has to be performed towing to the lack of tumour-specific regimes available and insufficient early tumour detection. Currently, the prediction of tumour progression or recurrence is limited to the use of histopathological and clinical factors, such as tumour size, histological grade, histological subtype or age at diagnosis (Fesinmeyer et al, 2005; Schmidt et al, 2008; Matos et al, 2009). The identification of novel prognostic factors might enable a better risk stratification for adjuvant treatment modalities after surgery or more aggressive treatment in patients with primary metastatic disease. External validation of prognostic risk assessment tools in independent cohorts of patients is paramount before the generalisation of the applicability of a prognostic marker or model (Bleeker et al, 2003). Changes in the systemic inflammatory response to tumour cell manifestation or systemic inflammation at all can be easily measured by blood-based parameters such as erythrocyte sedimentation rate, C-reactive protein (CRP) or different levels of white blood cells, with, for example, a better outcome for a high density of lymphocytes in tumour stroma than a lower one (Clark et al, 2007). Importantly, especially the neutrophil-lymphocyte ratio (NLR) has been assumed to be an easily available and trustable marker to predict patients' survival in different types of cancer (Roxburgh and McMillan, 2010). In the last years, these findings have been proven within several tumour entities regarding its role in prediction of cancer progression and prognosis (Teramukai et al, 2009; Jung et al, 2011; Mallappa et al, 2013; Pichler et al, 2013). In PC, controversial data exist regarding NLR and tumour outcome, but most of these studies included rather small numbers of investigated cases $(n<100)$ and differ in terms of inclusion criteria and clinical end points (Clark et al, 2007; Sanjay et al, 2012; Wang et al, 2012). Therefore, the aim of our study was to externally validate the value of NLR as a prognostic parameter in a large cohort of 371 PC patients. For this purpose, we tested the prognostic relevance of NLR with regard to cancerspecific survival (CSS), stratified for (A) patients who underwent surgical resection (group 1) and (B) patients who were inoperable at the time of diagnosis (group 2).

\section{MATERIALS AND METHODS}

This retrospective analysis included data from 371 consecutive patients with histologically confirmed pancreatic adenocarcinoma, who were treated at the Division of Clinical Oncology, Medical University of Graz between 2004 and 2010. All clinico-pathological data were retrieved from medical records at the Division of Clinical Oncology and pathological records from the Institute of Pathology at the same institution.

As the TNM classification system for PC changed during the study period, tumour stages were uniformly adjusted according to the 7th edition of this system. Other documented clinicopathological parameters included type of therapy (i.e., surgical intervention or primary inoperable disease state), administration and mode (adjuvant or palliative) of chemotherapy with gemcitabine, gender and age. The laboratory data, including neutrophil, lymphocyte, platelet counts, levels of albumin, CRP, levels of tumour markers CA19-9 and CEA and bilirubin levels were obtained by pre-operative exploration 1 week-1 day before surgical intervention or histologically proven diagnosis. On the basis of previous studies, a NLR of $>5$ was selected as the cut-off value for validation (Garcea et al, 2011; Wang et al, 2012). In addition, we evaluated the prognostic value of the plateletlymphocyte ratio (PLR) and the modified Glasgow prognostic score (mGPS), as previously described (Proctor et al, 2011; Wang et al, 2012). The PLR was categorised into two groups according to a cut-off value of $>150$ (Wang et al, 2012). The mGPS combines CRP and albumin concentrations. Patients who had both elevated CRP $\left(>10 \mathrm{mg} \mathrm{dl}^{-1}\right)$ and decreased albumin levels $\left(<3.5 \mathrm{~g} \mathrm{dl}^{-1}\right)$ were assigned a score of 2 . Patients with only elevated CRP $\left(>10 \mathrm{mg} \mathrm{dl}^{-1}\right)$ were assigned a score of 1 and patients with neither of these abnormalities were assigned a score of 0 (Proctor et al, 2011). Patients' post-operative surveillance included routine clinical and laboratory examination and imaging methods. Followup evaluations were performed every 3 months within the first 3 years, 6 months for 5 years and annually thereafter for curative resected tumour stages. For deceased patients, dates of death were obtained from the central registry of the Austrian Bureau of Statistics. Cancer-specific survival was defined as the time (in months) from the date of surgery or date of histologically proven diagnosis to cancer-related death. The study was approved by the local ethical committee of the Medical University of Graz (No. 23-279 ex 10/11).

Statistical analyses. For external validation of the prognostic value of the inflammatory parameters, we decided to use a prognostic subdivision for each described prognostic parameter or score that is consistent with the previously published literature. The relationship between NLR and other clinico-pathological parameters was studied by non-parametric tests. Patients' clinical end points were calculated using the Kaplan-Meier method and compared by the log-rank test. Gender, age and all variables with significant prognostic value in univariate analysis were selected for further evaluation in the final multivariate Cox proportionalhazard model. Backward stepwise multivariate Cox proportion analysis was performed to determine the influence of different clinico-pathological parameters on CSS. Hazard ratios (HRs) estimated from the Cox analysis were reported as relative risks with corresponding 95\% confidence intervals (CIs). All statistical analyses were performed using the Statistical Package for Social Sciences version 17.0 (SPSS Inc., Chicago, IL, USA). A two-sided $P<0.05$ was considered statistically significant.

\section{RESULTS}

Of the 371 consecutive PC patients, 261 (70.4\%) patients were diagnosed without a chance of curative surgical intervention owing to the advanced disease state (group 1). The other 110 (29.6\%) patients underwent a resection of their tumour-bearing pancreas (group 2). The median survival time of patients from the whole cohort was 7 months (interquartile range: 3-17 months). Overall, we found a mean neutrophil count of $5432 \pm 2846$, a mean lymphocyte count of $1421 \pm 606$ and a mean NLR of $4.75 \pm 5.67$. Applying the criteria mentioned above, we selected a cut-off value of $>5$ for the external validation of the prognostic relevance of NLR. Regarding group 1 (261 primary inoperable patients), median survival was 5 (interquartile range: $2-12$ ) months and 257 (98.5\%) patients died by their most recent follow-up visit. Table 1 summarises the clinico-pathological parameters of group 1. Of the 261 inoperable patients, 221 (84.7\%) had metastatic PC and 40 (15.3\%) had locally advanced inoperable PC. Of the 261 inoperable patients, $179(68.6 \%)$ received a palliative chemotherapeutic treatment with gemcitabine monotherapy. A NLR $\geqslant 5$ was statistically significantly correlated with a non-administration of chemotherapy, metastatic disease at diagnosis, high mGPS, high PLR and higher CA19-9 levels $(P<0.05)$, but not with age, CEA levels or gender. 


\begin{tabular}{|c|c|}
\hline Parameter & Number of pancreatic cancer (\%) \\
\hline \multicolumn{2}{|c|}{ Age at diagnosis (years) } \\
\hline$<65$ & $111(42.5)$ \\
\hline$\geqslant 65$ & $150(57.5)$ \\
\hline \multicolumn{2}{|l|}{ Gender } \\
\hline Male & $103(39.5)$ \\
\hline Female & $158(60.5)$ \\
\hline \multicolumn{2}{|l|}{ Tumor spread } \\
\hline Locally advanced & $40(15.3)$ \\
\hline Metastatic & $221(84.7)$ \\
\hline \multicolumn{2}{|l|}{ Chemotherapy } \\
\hline No chemotherapy & $82(31.4)$ \\
\hline Chemotherapy & $179(68.6)$ \\
\hline \multicolumn{2}{|c|}{ Neutrophil-lymphocyte ratio } \\
\hline$<5$ & $182(69.7)$ \\
\hline$\geqslant 5$ & 79 (30.3) \\
\hline \multicolumn{2}{|c|}{ Platelet-lymphocyte ratio } \\
\hline$<150$ & $102(39.1)$ \\
\hline$\geqslant 150$ & 159 (60.9) \\
\hline \multicolumn{2}{|c|}{ Modified Glasgow prognostic score } \\
\hline 0 & $117(44.8)$ \\
\hline 1 & $115(44.1)$ \\
\hline 2 & $29(11.1)$ \\
\hline
\end{tabular}

To investigate whether a high NLR is associated with the clinical outcome of group 1 (i.e. primary inoperable PC) patients, univariable and multivariable analysis was performed. Figure 1 shows the Kaplan-Meier curve for CSS and reveals that a high NLR is a consistent factor for poor prognosis in inoperable PC patients $(P<0.001$, log-rank test $)$.

Univariate analysis identified metastatic PC (metastatic vs locally advanced, $P<0.001)$, no chemotherapeutic treatment (no treatment $v s$ palliative chemotherapy, $P<0.001$ ), increased NLR $(\geqslant 5$ vs $<5, P<0.001)$ and high mGPS $(1+2 v s 0, P=0.029)$ as prognosticators of poor outcome for patients' CSS, whereas gender, age and PLR were not statistically significantly associated with CSS (Table 2).

To determine the independent prognostic significance of the NLR for CSS, a multivariate Cox proportional-hazard model including gender, age and all variables significantly associated with survival in univariable analysis was calculated. In the multivariate analysis, we identified metastatic disease at diagnosis, no administration of palliative chemotherapy and an increased NLR (all $P$-values $<0.05$, Table 2) as independent prognostic factors for CSS.

Regarding group 2 (110 PC patients who underwent a surgical resection with curative intention), median survival was 18 (interquartile range: $8-25)$ months and $84(76.4 \%)$ patients died by their most recent follow-up visit. Of the 110 patients, 16 (14.5\%) had locally confined tumours (stage I-IIa), 85 (77.3\%) had lymph node involvement (stage IIb) and 9 (8.2\%) had locally advanced disease (stage III). Eighty-nine $(80.9 \%)$ had a R0 resection with free surgical margins and $88(80 \%)$ patients received a treatment with gemcitabine. Thirty-seven (33.6\%) patients had an increased NLR ( $\geqslant 5$ as defined above as the cut-off value, Table 3 ). Increased NLR was significantly associated with high mGPS and high PLR but not

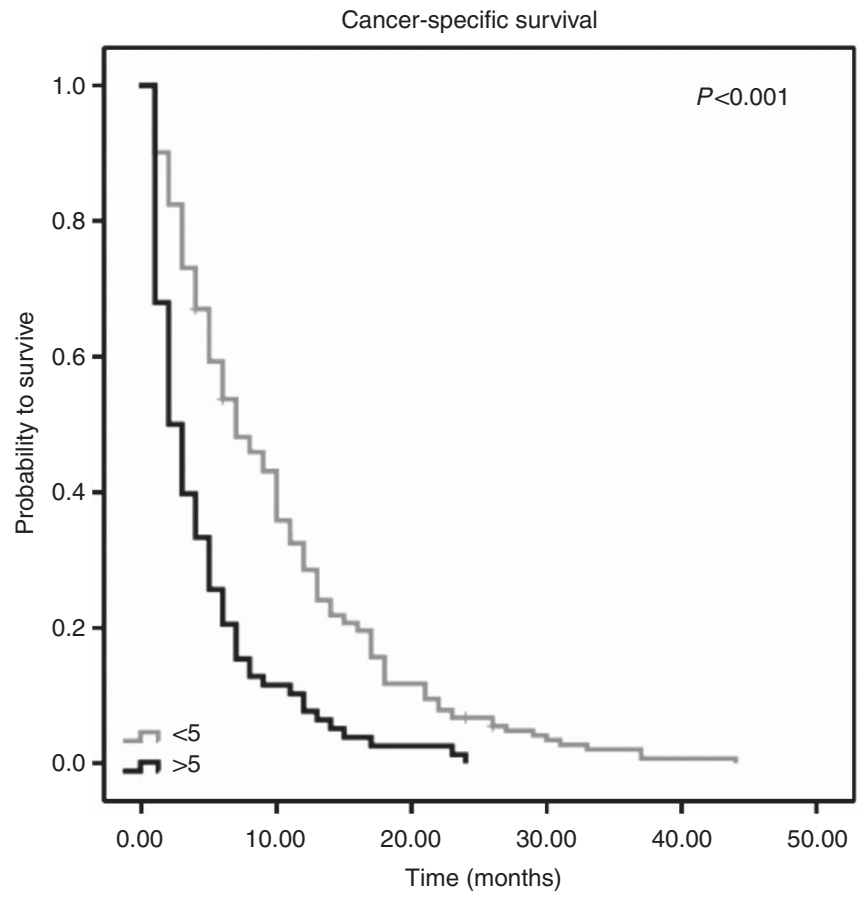

Figure 1. Kaplan-Meier curve stratified by NLR regarding cancerspecific survival for patients with primary inoperable pancreatic adenocarcinoma $(n=261)$.

statistically significantly correlated with age, tumour stage, resection margin, administration of chemotherapy, gender or pre-operative levels of bilirubin, CA19-9 or CEA (data not shown).

Univariate analysis identified advanced disease state (stage IIb/ III $v s$ stage I-IIa, $P<0.001$ ), free surgical margin (R0 resection $v s$ R1 resection, $P=0.019)$ and increased NLR $(\geqslant 5 v s<5, P<0.006)$ as prognosticators of poor outcome for patients' CSS, whereas gender, age, mGPS, PLR and administration of chemotherapy (all $P$-values $<0.05)$ were not statistically significantly associated with CSS (Table 4). Figure 2 shows the Kaplan-Meier curve for CSS and reveals that a high NLR is a factor for poor prognosis in PC patients who underwent a tumour resection $(P=0.005$, log-rank test).

To determine the independent prognostic significance of the NLR for CSS, a multivariate Cox proportional-hazard model was calculated including gender, age and all variables significantly associated with survival in univariate analysis. In the multivariate analysis, we identified advanced disease state and an increased NLR as independent prognostic factors for CSS (Table 4).

\section{DISCUSSION}

Owing to hardly any major progress - despite tremendous research activities - in tumour-specific therapy in PC in the last years, insufficient early tumour diagnosis and non-effective therapy regimes still stay a great challenge. Up to now, the initial tumour stage and possibility of curative resection have tipped the balance for further oncological therapy decision. However, most patients have to rely on palliative chemotherapy owing to failure of surgical resection at the time of diagnosis (Sun et al, 2012). In order to gain more prognostic information than pathological tissue examination or traditional clinico-pathological variables in PC, we did this external validation study in two different patient groups and confirmed that an increased NLR is an independent prognostic factor for primary operable PC and for already advanced PC. The 
Table 2. Univariate and multivariate analysis of clinico-pathological parameters for the prediction of cancer-specific survival in patients with inoperable pancreatic cancer $(n=261)$

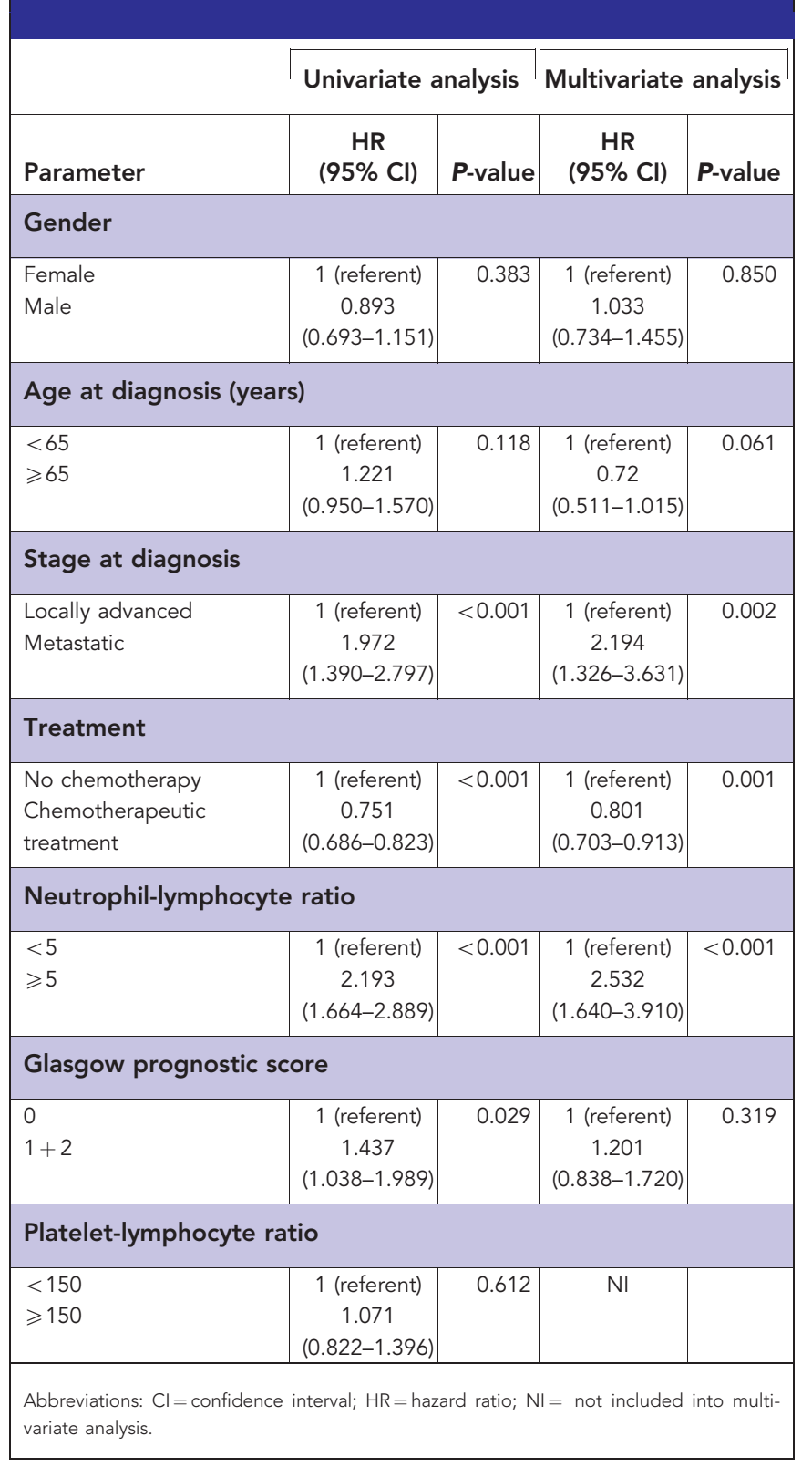

knowledge about the bilateral influence of cancer and inflammation had been discovered over a century ago. However, interest in this topic has revived in the last few years, when several studies including those of Allavena et al (2008) and Mantovani et al (2008), for example, could give further insights into the tumour-toinflammation relationship. Beyond the pathophysiological mechanisms and interactions of inflammatory tumour stroma and cancer cells, inflammatory circulating molecules and cells attract more and more attention as prognostic biomarkers. Especially the NLR and its role as a prognostic marker in several different tumour entities was intensively explored, where a correlation between high NLR and poor clinical outcome could be obtained. The easily available blood-based parameters for computing the NLR - without any further laborious efforts - could make this value a good parameter for a more individualised risk assessment in PC. In PC, until now there is only small and controversial evidence for NLR's role as a prognostic marker owing to the fact that small account of studies and a limited patient
Table 3. Clinico-pathological parameters of patients with operable pancreatic cancer $(n=110)$

\begin{tabular}{|l|c|}
\hline Parameter & Number of pancreatic cancer (\%) \\
\hline \multicolumn{2}{|l|}{ Age at operation (years) } \\
\hline$<65$ & $55(50)$ \\
$\geqslant 65$ & $55(50)$
\end{tabular}

\begin{tabular}{|l|c|}
\hline \multicolumn{2}{|l|}{ Gender } \\
\hline Male & $51(46.4)$ \\
Female & $59(53.6)$ \\
\hline UICC stage \\
\hline IB \\
IIA & $2(1.8)$ \\
IIB & $14(12.7)$ \\
III & $85(77.3)$ \\
\hline
\end{tabular}

\begin{tabular}{|l|l|}
\hline Chemotherapy \\
\hline $\begin{array}{l}\text { No chemotherapy } \\
\text { Chemotherapy }\end{array}$ & $22(20)$ \\
\hline & $88(80)$ \\
\hline
\end{tabular}

\begin{tabular}{|l|l|}
\hline \multicolumn{2}{|l|}{ Resection margin } \\
\hline R0 & $89(80.9)$ \\
R1 & $21(19.1)$ \\
\hline \multicolumn{2}{|l|}{ Neutrophil-lymphocyte ratio } \\
\hline$<5$ & $73(66.4)$ \\
$\geqslant 5$ & $37(33.6)$ \\
\hline Platelet-lymphocyte ratio & \\
\hline$<150$ & $28(25.5)$ \\
$\geqslant 150$ & $82(74.5)$ \\
\hline Modified Glasgow prognostic score \\
\hline 0 & \\
1 & $73(66.7)$ \\
2 & $21(19)$ \\
\hline
\end{tabular}

number have to be clarified more accurately. For instance, Clark et al (2007) evaluated 44 primary resected PC patients and found no prognostic relevance for increased NLR. Another negative study including 51 primary resected PC patients was reported by Sanjay et al (2012). In contrast to these negative findings and in line with our data, Wang et al (2012) found a poorer prognosis in 177 consecutive PC (regardless of their therapeutic strategy) patients in case of elevated NLR. Garcea et al (2011) could also prove NLR, in 74 PC patients, as a significant prognostic parameter regarding disease-free survival . Interestingly, the results of the study by Wang et al (2012) corroborate with our findings regarding the lack of significant prognostic information of the mGPS and the PLR in PC patients. In contrast to our data and the study by Wang et al (2012), Jamieson et al (2011) reported in 135 surgically treated patients that mGPS but not NLR or PLR, were independent prognostic factors. Pine et al (2009) also found a relationship of elevated CRP levels and poor survival in 141 inoperable PC patients. Some reasons for these contrastive results might be the small number of investigated cases reported in many previous studies, different cut-offs used for CRP, different inclusion and exclusion criteria and different treatment schedules. However, all stated investigations had to deal with smaller patient accounts, and to the best of our knowledge our study represents the most comprehensive one up to now, validating a previously proposed cut-off value and the independent prognostic significance of the 
Table 4. Univariate and multivariate analysis of clinico-pathological parameters for the prediction of cancer-specific survival in patients with operable pancreatic cancer $(n=110)$

\begin{tabular}{|c|c|c|c|c|}
\hline \multirow[b]{2}{*}{ Parameter } & \multicolumn{2}{|c|}{ Univariate analysis } & \multicolumn{2}{|c|}{$\begin{array}{c}\text { Multivariate } \\
\text { analysis }\end{array}$} \\
\hline & $\begin{array}{c}\mathrm{HR} \\
(95 \% \mathrm{Cl})\end{array}$ & $\boldsymbol{P}$-value & $\begin{array}{c}\mathrm{HR} \\
(95 \% \mathrm{Cl})\end{array}$ & $P$-value \\
\hline \multicolumn{5}{|l|}{ Gender } \\
\hline $\begin{array}{l}\text { Female } \\
\text { Male }\end{array}$ & $\begin{array}{c}1 \text { (referent) } \\
0.901 \\
(0.583-1.394)\end{array}$ & 0.641 & $\begin{array}{c}1 \text { (referent) } \\
0.771 \\
(0.494-1.203)\end{array}$ & 0.252 \\
\hline \multicolumn{5}{|c|}{ Age at operation (years) } \\
\hline $\begin{array}{l}<65 \\
\geqslant 65\end{array}$ & $\begin{array}{c}1 \text { (referent) } \\
1.440 \\
(0.930-2.229)\end{array}$ & 0.102 & $\begin{array}{c}1 \text { (referent) } \\
1.522 \\
(0.973-2.379)\end{array}$ & 0.066 \\
\hline \multicolumn{5}{|c|}{ Stage at diagnosis } \\
\hline $\begin{array}{l}\text { Stage I/Ila } \\
\text { Stage Ilb/III }\end{array}$ & $\begin{array}{c}1 \text { (referent) } \\
3.686 \\
(2.006-6.770)\end{array}$ & $<0.001$ & $\begin{array}{c}1 \text { (referent) } \\
2.923 \\
(1.563-5.466)\end{array}$ & 0.001 \\
\hline \multicolumn{5}{|l|}{ Treatment } \\
\hline $\begin{array}{l}\text { No chemotherapy } \\
\text { Chemotherapeutic } \\
\text { treatment }\end{array}$ & $\begin{array}{c}1 \text { (referent) } \\
0.779 \\
(0.596-1.020)\end{array}$ & 0.069 & $\mathrm{NI}$ & \\
\hline \multicolumn{5}{|c|}{ Neutrophil-lymphocyte ratio } \\
\hline $\begin{array}{l}<5 \\
\geqslant 5\end{array}$ & $\begin{array}{c}1 \text { (referent) } \\
1.852 \\
(1.198-2.865)\end{array}$ & 0.006 & \begin{tabular}{|c|}
1 (referent) \\
1.611 \\
$(1.024-2.534)$ \\
\end{tabular} & 0.039 \\
\hline \multicolumn{5}{|c|}{ Glasgow prognostic score } \\
\hline $\begin{array}{l}0 \\
1+2\end{array}$ & $\begin{array}{c}1 \text { (referent) } \\
1.095 \\
(0.791-1.516)\end{array}$ & 0.585 & $\mathrm{NI}$ & \\
\hline \multicolumn{5}{|c|}{ Platelet-lymphocyte ratio } \\
\hline $\begin{array}{l}<150 \\
\geqslant 150\end{array}$ & $\begin{array}{c}1 \text { (referent) } \\
1.133 \\
(0.815-1.574)\end{array}$ & 0.458 & $\mathrm{NI}$ & \\
\hline \multicolumn{5}{|l|}{ Resection margin } \\
\hline $\begin{array}{l}\mathrm{R} 0 \\
\mathrm{R} 1\end{array}$ & $\begin{array}{c}1 \text { (referent) } \\
1.884 \\
(1.110-3.199) \\
\end{array}$ & 0.019 & $\begin{array}{c}1 \text { (referent) } \\
1.699 \\
(0.951-3.035) \\
\end{array}$ & 0.073 \\
\hline $\begin{array}{l}\text { Abbreviations: } \mathrm{Cl}=\mathrm{co} \\
\text { variate analysis. }\end{array}$ & erval; $H R=$ hazar & d ratio; $\mathrm{NI}=$ & $=$ not included in & to multi- \\
\hline
\end{tabular}

NLR. On the basis of our data, we believe that determining the NLR at the time of PC diagnosis might be useful as a stratification criterion in clinical trials, as the survival of patients who receive medical treatment schedules can massively be influenced by (unknown) prognostic parameters. Thus, imbalanced stratification of patients according to yet unrecognised prognostic factors such as the NLR might impact the outcome of clinical trials and influences consecutive approval/rejection of novel tested anticancer drugs. Besides potential for a risk stratification criterion in clinical trials, the pretreatment of NLR might also be helpful for individual patient's risk assessment and the patient's counselling. Up to now, there is no clear biological explanation for all these findings;

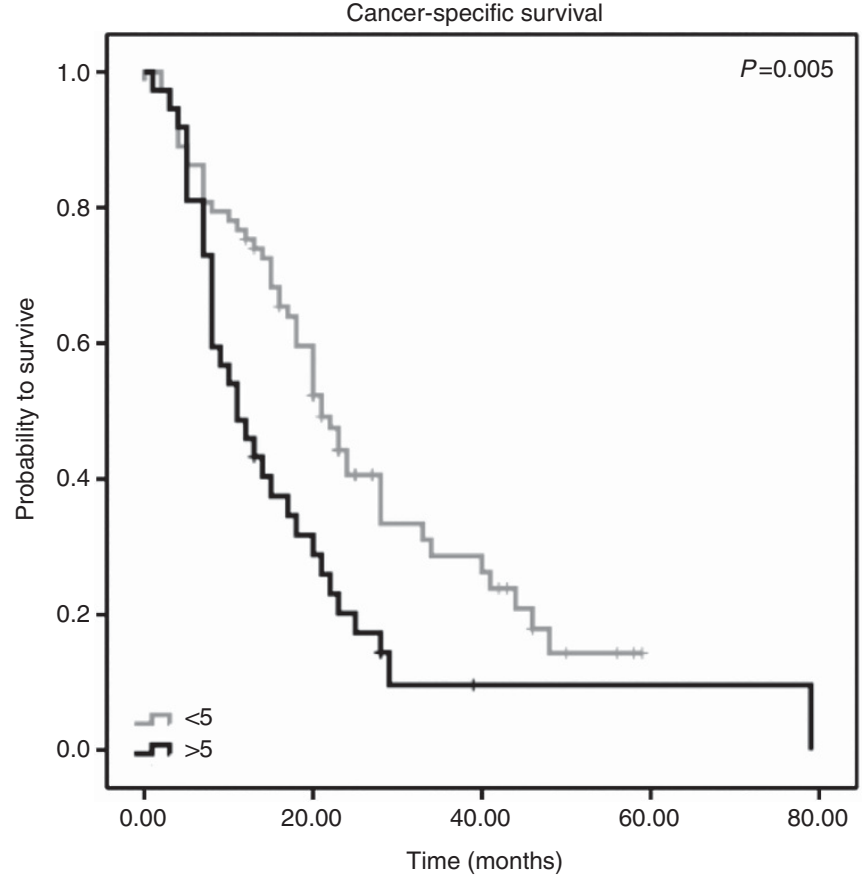

Figure 2. Kaplan-Meier curve stratified by NLR regarding cancerspecific survival for patients with primary resected pancreatic adenocarcinoma $(n=110)$.

however, some postulations regarding these facts have been made. Activation of intracellular pathways, such as K-Ras/RAF/MEK signalling was shown as a stimulating procedure for accumulation of neutrophils in tumour microenvironment, followed by intensive inflammatory response (Ji et al, 2006). Furthermore, a large amount of neutrophils, which had been reported to influence cytolytic activity of lymphocytes or natural killer cells over 20 years ago, could influence tumour growth in a negative way. Recent research activities identified neutrophils, respectively, neutrophil subpopulations that suppressed T-cell proliferation by integrin Mac-1 and hydrogen peroxide (Pillay et al, 2012). As a high NLR goes along with either a larger neutrophil amount or a lower number of lymphocytes, logically a higher NLR can result in a relative lymphopenia. Lymphocytes are known to have a crucial role in tumour defence by inducing cytotoxic cell death and inhibiting tumour cell proliferation and migration (Coussens and Werb, 2002; Mantovani et al, 2008). Therefore, a reduced number of lymphocytes lead to a weaker immune reaction against tumour cells. Furthermore, immunological importance of neutrophil and lymphatic cells in other diseases, like those of cardiocvascular, endocrinological or infectious type, has been found in different investigations (Tsai et al, 2007; Imtiaz et al, 2012; Terradas et al, 2012). Nonetheless, in this connection it should not be forgotten that albeit NLR is easy to measure, the number of neutrophils and lymphocytes strongly depends on a range of internal and external factors, from active infection, chronic inflammatory diseases up to lifestyle-related habits (Buyukkaya et al, 2012).

As with all retrospective studies, limitations of our study are inherent to its design including the retrospective data collection. Nonetheless, we were able to show that an elevated NLR is a poor prognostic marker for patients with primary operable and metastatic PC. One of the strengths of our study is the relatively large sample size in comparison with other studies covering this issue. However, counting the NLR ratio gives an independent prognostic hint and may be a support for oncological therapy decisions. Clarifying the optimal NLR cut-off level and further investigations of its strength and weaknesses are warranted. 


\section{ACKNOWLEDGEMENTS}

This study was supported by funds from the Oesterreichische Nationalbank (Anniversary Fund, Project number: 14320 to Gerald Hoefler).

\section{CONFLICT OF INTEREST}

The authors declare no conflict of interest.

REFERENCES

Allavena P, Garlanda C, Borrello MG, Sica A, Mantovani A (2008) Pathways connecting inflammation and cancer. Curr Opin Genet Dev 18(1): 3-10.

Bleeker SE, Moll HA, Steyerberg EW, Donders AR, Derksen-Lubsen G, Grobbee DE, Moons KG (2003) External validation is necessary in prediction research: a clinical example. J Clin Epidemiol 56(9): 826-832.

Buyukkaya E, Karakas MF, Karakas E, Akcay AB, Kurt M, Tanboga IH, Sen N (2012) Correlation of neutrophil to lymphocyte ratio with the presence and severity of metabolic syndrome. Clin Appl Thromb Hemost.

Clark EJ, Connor S, Taylor MA, Madhavan KK, Garden OJ, Parks RW (2007) Preoperative lymphocyte count as a prognostic factor in resected pancreatic ductal adenocarcinoma. HPB (Oxford) 9(6): 456-460.

Coussens LM, Werb Z (2002) Inflammation and cancer. Nature 420(6917): 860-867.

David M, Lepage C, Jouve JL, Jooste V, Chauvenet M, Faivre J, Bouvier AM (2009) Management and prognosis of pancreatic cancer over a 30-year period. Br J Cancer 101(2): 215-218.

Fesinmeyer MD, Austin MA, Li CI, De Roos AJ, Bowen DJ (2005) Differences in survival by histologic type of pancreatic cancer. Cancer Epidemiol Biomarkers Prev 14(7): 1766-1773.

Garcea G, Ladwa N, Neal CP, Metcalfe MS, Dennison AR, Berry DP (2011) Preoperative neutrophil-to-lymphocyte ratio (NLR) is associated with reduced disease-free survival following curative resection of pancreatic adenocarcinoma. World J Surg 35(4): 868-872.

Imtiaz F, Shafique K, Mirza SS, Ayoob Z, Vart P, Rao S (2012) Neutrophil lymphocyte ratio as a measure of systemic inflammation in prevalent chronic diseases in Asian population. Int Arch Med 5(1): 2.

Jamieson NB, Denley SM, Logue J, MacKenzie DJ, Foulis AK, Dickson EJ, Imrie CW, Carter R, McKay CJ, McMillan DC (2011) A prospective comparison of the prognostic value of tumor- and patient-related factors in patients undergoing potentially curative surgery for pancreatic ductal adenocarcinoma. Ann Surg Oncol 18(8): 2318-2328.

Ji H, Houghton AM, Mariani TJ, Perera S, Kim CB, Padera R, Tonon G, McNamara K, Marconcini LA, Hezel A, El-Bardeesy N, Bronson RT, Sugarbaker D, Maser RS, Shapiro SD, Wong KK (2006) K-ras activation generates an inflammatory response in lung tumors. Oncogene 25(14): 2105-2112.

Jung MR, Park YK, Jeong O, Seon JW, Ryu SY, Kim DY, Kim YJ (2011) Elevated preoperative neutrophil to lymphocyte ratio predicts poor survival following resection in late stage gastric cancer. J Surg Oncol 104(5): 504-510.

Mallappa S, Sinha A, Gupta S, Chadwick S (2013) Preoperative neutrophil lymphocyte ratio greater than five is a prognostic factor for recurrent colorectal cancer. Colorectal Dis 15(3): 323-328.

Mantovani A, Allavena P, Sica A, Balkwill F (2008) Cancer-related inflammation. Nature 454(7203): 436-444.

Matos JM, Schmidt CM, Turrini O, Agaram NP, Niedergethmann M, Saeger HD, Merchant N, Johnson CS, Lillemoe KD, Grutzmann R (2009) Pancreatic acinar cell carcinoma: a multi-institutional study. J Gastrointest Surg 13(8): 1495-1502.

Pichler M, Hutterer GC, Stoeckigt C, Chromecki TF, Stojakovic T, Golbeck S, Eberhard K, Gerger A, Mannweiler S, Pummer K, Zigeuner R (2013) Validation of the pre-treatment neutrophil-lymphocyte ratio as a prognostic factor in a large European cohort of renal cell carcinoma patients. Br J Cancer 108(4): 901-907.

Pillay J, Kamp VM, van Hoffen E, Visser T, Tak T, Lammers JW, Ulfman LH, Leenen LP, Pickkers P, Koenderman L (2012) A subset of neutrophils in human systemic inflammation inhibits T cell responses through Mac-1. $J$ Clin Invest 122(1): 327-336.

Pine JK, Fusai KG, Young R, Sharma D, Davidson BR, Menon KV, Rahman SH (2009) Serum C-reactive protein concentration and the prognosis of ductal adenocarcinoma of the head of pancreas. Eur J Surg Oncol 35(6): 605-610.

Proctor MJ, Morrison DS, Talwar D, Balmer SM, O’Reilly DS, Foulis AK, Horgan PG, McMillan DC (2011) An inflammation-based prognostic score (mGPS) predicts cancer survival independent of tumour site: a Glasgow Inflammation Outcome Study. Br J Cancer 104(4): 726-734.

Roxburgh CS, McMillan DC (2010) Role of systemic inflammatory response in predicting survival in patients with primary operable cancer. Future Oncol 6(1): 149-163.

Sanjay P, de Figueiredo RS, Leaver H, Ogston S, Kulli C, Polignano FM, Tait IS (2012) Preoperative serum C-reactive protein levels and postoperative lymph node ratio are important predictors of survival after pancreaticoduodenectomy for pancreatic ductal adenocarcinoma. JOP 13(2): 199-204.

Schmidt CM, Matos JM, Bentrem DJ, Talamonti MS, Lillemoe KD, Bilimoria KY (2008) Acinar cell carcinoma of the pancreas in the United States: prognostic factors and comparison to ductal adenocarcinoma. J Gastrointest Surg 12(12): 2078-2086.

Sharma C, Eltawil KM, Renfrew PD, Walsh MJ, Molinari M (2011) Advances in diagnosis, treatment and palliation of pancreatic carcinoma: 1990-2010. World J Gastroenterol 17(7): 867-897.

Siegel R, Naishadham D, Jemal A (2012) Cancer statistics, 2012. CA Cancer J Clin 62(1): 10-29.

Sun C, Ansari D, Andersson R, Wu DQ (2012) Does gemcitabine-based combination therapy improve the prognosis of unresectable pancreatic cancer? World J Gastroenterol 18(35): 4944-4958.

Teramukai S, Kitano T, Kishida Y, Kawahara M, Kubota K, Komuta K, Minato K, Mio T, Fujita Y, Yonei T, Nakano K, Tsuboi M, Shibata K, Furuse K, Fukushima M (2009) Pretreatment neutrophil count as an independent prognostic factor in advanced non-small-cell lung cancer: an analysis of Japan Multinational Trial Organisation LC00-03. Eur J Cancer 45(11): 1950-1958.

Terradas R, Grau S, Blanch J, Riu M, Saballs P, Castells X, Horcajada JP, Knobel H (2012) Eosinophil count and neutrophil-lymphocyte count ratio as prognostic markers in patients with bacteremia: a retrospective cohort study. PloS One 7(8): e42860.

Tinchon C, Hubmann E, Pichler A, Keil F, Pichler M, Rabl H, Uggowitzer M, Jilek K, Leitner G, Bauernhofer T (2013) Safety and efficacy of neoadjuvant FOLFIRINOX treatment in a series of patients with borderline resectable pancreatic ductal adenocarcinoma. Acta Oncol; e-pub ahead of print 27 February 2013.

Tsai JC, Sheu SH, Chiu HC, Chung FM, Chang DM, Chen MP, Shin SJ, Lee YJ (2007) Association of peripheral total and differential leukocyte counts with metabolic syndrome and risk of ischemic cardiovascular diseases in patients with type 2 diabetes mellitus. Diabetes Metab Res Rev 23(2): $111-118$.

Tummala P, Junaidi O, Agarwal B (2011) Imaging of pancreatic cancer: An overview. J Gastrointest Oncol 2(3): 168-174.

Wang DS, Luo HY, Qiu MZ, Wang ZQ, Zhang DS, Wang FH, Li YH, Xu RH (2012) Comparison of the prognostic values of various inflammation based factors in patients with pancreatic cancer. Med Oncol 29(5): 3092-3100.

This work is published under the standard license to publish agreement. After 12 months the work will become freely available and the license terms will switch to a Creative Commons AttributionNonCommercial-Share Alike 3.0 Unported License. 